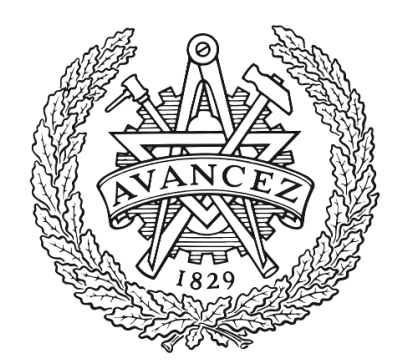

\title{
CHALMERS
}

UNIVERSITY OF TECHNOLOGY

\section{Comparison of Car-Following Behavior in Terms of Safety Indicators Between China and Sweden}

Downloaded from: https://research.chalmers.se, 2023-04-26 11:46 UTC

Citation for the original published paper (version of record):

Liu, T., Selpi, S. (2020). Comparison of Car-Following Behavior in Terms of Safety Indicators Between China and Sweden. IEEE Transactions on Intelligent Transportation Systems, 21(9): 3696-3705. http://dx.doi.org/10.1109/TITS.2019.2931797

N.B. When citing this work, cite the original published paper.

(C2020 IEEE. Personal use of this material is permitted.

However, permission to reprint/republish this material for advertising or promotional purposes 


\title{
Comparison of car-following behaviour in terms of safety indicators between China and Sweden
}

\author{
Tong Liu and Selpi
}

\begin{abstract}
Understanding car-following behaviour in different countries is essential for the design and development of autonomous driving and further development of active safety systems that can function well worldwide, in particular in mixed traffic conditions. However, very few studies exist that compare car-following behaviours in different countries based on real driving data. This paper analyses the similarities and differences of drivers' car-following behaviour, in terms of time gap, gap distance, and time to collision, using both China and Sweden datasets from real road driving studies, in a bid to identify how these indicators affect drivers' speed control in car-following situations. Results indicate that the highest frequency of gap distance is observed in the same value-range in both datasets, while the highest frequency of time gap in the Sweden dataset is found at a lower value-range than the corresponding value-range in the China dataset. For both datasets, time gap is observed to be a more reliable indicator for car-following analysis than gap distance, since it is less sensitive to speed variations. Furthermore, time to collision (TTC) in the low travel speed ranges $(\mathrm{v}<50 \mathrm{~km} / \mathrm{h})$ tends to be steady in comparison with TTC at other speed ranges, so is the time gap in the high speed ranges $(v>90 \mathrm{~km} / \mathrm{h})$. Therefore, time gap is recommended as the safety indicator for car-following analysis in high speed conditions, while a combination of time gap and TTC is recommended for low speed conditions, especially on urban roads.
\end{abstract}

Index Terms - Car-following, cross-cultural comparison, driving behaviour, safety indicator, time gap, time to collision.

\section{I . INTRODUCTION}

Car-following is one of the most important research issues in understanding driving behaviour because car-following behaviour does not only impacts traffic capacity or efficiency [1], but also plays an important role in traffic safety [2, 3]. Studying drivers' behaviour and identifying indicators that may impact their speed control in car-following situations is also important for designing the behaviour of automated vehicles, in particular to handle mixed traffic conditions where vehicles with different levels of automation are sharing the same roads.

Towards a holistic understanding of car-following behaviour, different studies have been done to investigate the types of indicators that are critical for safe car-following in

Tong Liu is with the School of Automobile, Chang'an University, Middle Section of Nan'er Huan Road, Xi'an 710064, China, and the Division of Vehicle Safety, Department of Mechanics and Maritime Sciences, Chalmers University of Technology, Gothenburg SE-412 96, Sweden (e-mail: liutong@chd.edu.cn).

Selpi is with the Division of Vehicle Safety, Department of Mechanics and Maritime Sciences, Chalmers University of Technology, Gothenburg SE-412 96, Sweden (e-mail: selpi@ chalmers.se). different countries. However, there have been very few studies comparing car-following behaviours of drivers in different countries based on field test data.

The main contribution of this paper is to analyse the similarities and differences of car-following behaviour in terms of safety indicators (time gap, gap distance, and time to collision) by using field test datasets from China and Sweden. This paper extends the work presented in [4], in which the relationship between safety indicators in car-following situations were investigated using data recorded through a real-road test in China. New material has been included with the purpose of creating a comparative study. This includes analysis of car-following behaviour in Sweden, comparison of car-following behaviour between China and Sweden, and a wider and deeper review of related works.

The most relevant related works are briefly reviewed here. Gap distance (distance as measured from the front bumper of the following vehicle to the back bumper of the preceding vehicle in a traffic stream) or time headway (THW, time between successive vehicles in a traffic lane as measured from front bumper to front bumper; this measure is usually available from an on-road sensor, but not from an in-vehicle sensor) have been suggested to have a significant effect on traffic capacity [5]. It was suggested in [6], that maximum road capacity is probably achieved at mean time headway of around 1.5 seconds (s), which is much shorter than the safety advice (to give at least 2-3 s gap) given to drivers in many countries [7, 8]. Besides that, a car-following gap model has been proposed to decrease the possibility of cut-in events by adjacent vehicles while ensuring the trade-off between safety and road capacity [9].

At present, safety indicators used to give warnings to drivers in car-following situations include time headway or time gap (time as measured from the front bumper of the following vehicle to the back bumper of the preceding vehicle; this is what usually available when the measurement is done by an in-vehicle sensor), gap distance or distance headway (DHW, the sum of gap distance and the length of the preceding vehicle; this measure is not usually available when the measurement is done by an in-vehicle sensor), time to collision (TTC, the expected time for the host vehicle to collide with the vehicle it follows if they remain on the same path and at the same speeds), time to accident (TA, the time to collide with other vehicles when evasive action has just been started by one of the road users if they continued with the same speeds and directions), safety margin (SM, a combination of time headway and TTC), etc. [10-14]. In addition to conventional TTCs, some modified TTC measures such as the time integrated TTC (TIT) and time exposed TTC 
(TET) have been recommended to further assess traffic safety [14]. Also, some studies suggested to use time headway as an indicator for high speed conditions and distance headway for low speed conditions [15], and to use time headway as the main determinant in conditions of longer distance and distance headway in conditions of short distance [16]. Furthermore, it has been shown that the lower the time headway or time gap is, the more likely a driver is involved in collisions or violations [17], and the greater the inverse TTC (1/TTC), the more risky a car-following situation will be [18].

Beside these, there have also been some studies that investigated the effect of road conditions and vehicle types on car-following behaviour. The analysis in [19] suggested that the distribution of gap distance varies significantly for different road conditions, while the relationship between gap distance and relative speed largely remain unchanged. In addition, it was observed in [17] that the time headway of 2-door cars is shorter than 4-door cars. In a study done in Iowa, an obvious difference in time gap was also observed for different vehicle types (car vs truck). The same study also found that time gap is relatively consistent in different urban freeway roads, while it is different for rural roads [20]. A different study conducted in Iran [21] showed that a car driver tends to keep a longer distance with a lead motorcycle in comparison with a lead car, and seems to be more prudent to use the gas/brake pedal if gap distance is less than $10 \mathrm{~m}$ when following a motorcycle compared with a similar situation when following a car.

Overall studies on car-following analysis and comparison between countries gave indications that drivers' behaviour vary among different countries. The analysis in [22] revealed that there is a significant difference in drivers' behaviour between the UK, France, and Germany; the time headways observed at free flow speeds in France were lower than those observed in Hamburg, which in turn were lower than those observed in the UK in similar condition. Different percentage of time is found to be spent in close following situations in three sites when the vehicle speed is above $80 \mathrm{~km} / \mathrm{h}$, and the lognormal distribution of time headway varies at different speed ranges. In a study by Pariota et al. [12], three experiments were conducted. One was conducted on a motorway in the UK by fitting a radar facing rearward to observe the following drivers. Another one was conducted in Italy by asking voluntary drivers to follow a corporate vehicle driven by an experimenter who has been asked to drive in a natural way. The last one was conducted on two motorways in Italy; drivers were asked to drive naturally in the first motorway and to follow a corporate vehicle in the second motorway. Based on these three experiments, it was found that the lognormal distribution of gap distance and the dispersion of gap distance between drivers increase with observed travel speed. In another comparison study [23], the car-following behaviour in the UK were compared with that in Japan. Drivers in Tsukuba, Japan were found to be more prone to take longer distance headway and to brake heavily when approaching a lead vehicle, while drivers in Southampton, the UK were found to prefer to keep shorter distance with lead vehicle and accelerate strongly when the speed of host vehicle is lower than the lead vehicle. Their analysis suggested that the desired time headway of Southampton drivers was just above $1.4 \mathrm{~s}$ for speed range $30-49 \mathrm{~km} / \mathrm{h}$ and just under $1 \mathrm{~s}$ for speed range $50-69 \mathrm{~km} / \mathrm{h}$, while the desired time headway of Tsukuba drivers was just above $1.6 \mathrm{~s}$ for speed range $30-49 \mathrm{~km} / \mathrm{h}$ and just under $1.2 \mathrm{~s}$ for speed range $50-69 \mathrm{~km} / \mathrm{h}$.

Therefore, it is important to understand the similarities and differences of drivers' behaviour and speed control strategy in car-following situations among countries, in a bid to develop corresponding active safety or warning systems compatible with driving styles or drivers' characteristics in different countries or regions. To broaden the cross-cultural research on car-following behaviour based on field test data, this paper presents a comparison of driving behaviour and several safety indicators affecting driver's speed control specifically in car-following using both China and Sweden datasets.

The remainder of this paper is organised as follows. Section 2 describes the field tests from which the data were gathered, and introduces the rules used in this study to extract car-following events. Section 3 shows the relationship of several safety indicators from different perspectives, presents the comparison of time gap and gap distance in various speed conditions, and describes the comparison of time gap and TTC with respect to various host vehicle speed ranges and relative speed ranges using datasets from China and Sweden. Section 4 discusses the results of our study and compares these with previous research. Finally, Section 5 concludes this paper and suggests directions for future work.

\section{II . METHODS}

\section{A. Field tests}

Two field tests were carried out independently: one in China and the other in Sweden. The dataset from China was collected in a real road driving around Huzhou district, Zhejiang province using an instrumented vehicle (Volkswagen Touran) equipped with multiple sensors. The dataset from Sweden was collected as part of the first European large-scale Field Operational Test on Active Safety Systems (euroFOT) [24] using Volvo cars for about one year in Gothenburg.

\section{B. Participants and apparatus}

The car-following data of 12 male drivers with age range 36-50 years old (mean age $=41.8$, standard deviation of age $=$ 4.3) and driving experience range 13-30 years (mean years of experience $=21.2$, standard deviation $=4.8$ ) were selected from the China dataset. All of the participants drove as they usually do in their daily driving during the real road driving test. The whole test session for each driver from China was about 70-90 minutes. The driving test was conducted on two kinds of routes: No.104 national highway and No.G25 Changshen expressway, with the speed limit of $70-90 \mathrm{~km} / \mathrm{h}$ and $110 \mathrm{~km} / \mathrm{h}$, respectively. In addition, the whole test routes were in good condition with few traffic jams or congestion, except at some intersections and traffic lights on No.104 national highway. The sensors included in the field test in China consisted of a 
millimetre wave radar with the range of 174 meters, field angle of $+/-10$ degrees and update grade of 50 milliseconds (to measure the relative angle/distance/speed between the host vehicle and the preceding vehicle), a CAN-bus acquisition card (to extract the host vehicle speed), and six camera monitoring systems (to record the front view, rear view, two side views, driver's face and pedal area). The camera systems were used as assistance in verifying uncertain car-following events after extraction. All of the recorded data in the China dataset (the relative angle, distance, and velocity to target vehicle and the host) were all sampled at $10 \mathrm{~Hz}$. The data such as TTC and time gap were calculated afterwards.

In the test of Sweden, each vehicle (Volvo V70 or XC70) was equipped with multi-sensors and logging device [25]. The recorded data includes GPS, speed, acceleration information as well as sensor information on lights, windshield wipers and type of road, etc. All data recording, including the recording of cameras, was done unobtrusively as to make the drivers feel they are not being observed. The data collection was done for a year. The car-following data of 24 drivers (11 female and 13 male) with age range 20-62 years old (mean age $=47.3$, standard deviation of age $=11.17$ ) were selected from the euroFOT dataset and the same kinds of car-following indicators within the speed limit of $70 / 90 / 110 \mathrm{~km} / \mathrm{h}$ were extracted and analysed here.

\section{Car-following events extraction}

The millimetre wave radar used in the field test in China could track 64 objects simultaneously. To identify and extract the target vehicle in front of the host vehicle during the whole driving session from the radar tracking, basic extraction rules were used. The extraction rules included the following checks; if the host vehicle and the preceding vehicle are running in the same lane, the relative angle (in absolute value) with the preceding vehicle is lower than 2 degrees, the host vehicle speed is greater than $10 \mathrm{~km} / \mathrm{h}$, and the upper limit value of gap distance or time gap is 120 meters or 6 seconds.

Once the target subject(s) have been identified and the car-following events have been extracted, the data nearby the start or/and the end point(s) of the extracted events were examined. Those that were found to be part of the car-following events through video verification even though the relative angle (in absolute value) with the preceding vehicle was not less than 2 degrees were included. In this way, the real start or/and end data point(s) of those extracted events can be determined manually.

Given that the size of China dataset and the comparison purpose with Sweden dataset in this study, relatively loose thresholds, to avoid missing any car-following events, were selected. A higher threshold for the host vehicle speed could certainly be used (i.e. $18 \mathrm{~km} / \mathrm{h}$, as suggested in most previous literatures) when extracting the car-following events in a large dataset in avoidance of congestion. The threshold used here for gap distance was as proposed in [26]. The THW threshold to distinguish a free-flow or car-following situation was suggested as 6 seconds in [16], therefore the threshold for time gap was set less than 6 seconds. The result of these extraction rules applied to one Chinese driver is shown here in Fig. 1. However, in the case of Sweden, we used the available car-following events directly with the help of coding from the SQL database. Note that the parameters were also recorded in the format of gap distance and time gap rather than DHW and THW in the Sweden dataset, and time gap was up to 4 seconds in the Sweden dataset when extracting the car-following events. Hence, the same criteria was also used in China dataset and the car-following events from China which have time gap up to 4 seconds were further extracted for comparison with the car-following events from the euroFOT dataset.

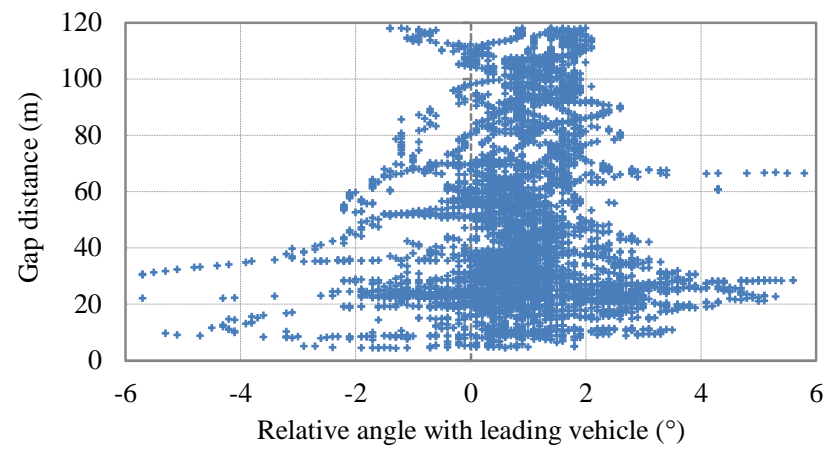

Fig. 1 Example of car-following data from one driver in China

\section{RESULTS}

\section{A. Distribution of safety indicators}

Fig. 2 shows the distribution of gap distance in various ranges from 12 Chinese drivers and 24 Swedish drivers among the whole car-following events. The gap distance data from both datasets were classified into groups based on the distance range, as such that the gap distance values within range of $(0-10 \mathrm{~m}]$ were grouped into group of $10 \mathrm{~m}$ and the values within range of $(10-20 \mathrm{~m}]$ were grouped into group of $20 \mathrm{~m}$, and so on. Fig. 2 also shows that the two highest frequencies of gap distance from both datasets are located within the range of $(20-30 \mathrm{~m}]$, which indicates that the drivers from China and Sweden are more likely to drive within that range of gap distance in car-following situations. After that range, the frequency starts to decrease gradually. Interestingly, the frequency of each gap distance range less than $40 \mathrm{~m}$ in Sweden dataset was higher compared to the frequency of corresponding range in China dataset, and the opposite was observed for gap distance ranges greater than $40 \mathrm{~m}$.

Likewise, the frequency of time gap in various ranges for all drivers is depicted in Fig. 3. Here, time gap within range of $(0-0.5 \mathrm{~s}]$ were classified into group of $0.5 \mathrm{~s}$ and the value within range of (0.5-1.0s] into group of $1.0 \mathrm{~s}$, and so on. As depicted in Fig. 3, the highest frequency of time gap was within the range of (1.5-2.0s] in China dataset and within the range of (1-1.5s] in Sweden dataset, the frequency starts to decrease gradually after the peak range. Similarly, one can find that the time gap ranges up to 2 seconds in Sweden dataset accounted for a larger proportion compared to the China dataset. However the opposite was observed for the time gap ranges greater than 2 seconds. 
In addition, Fig. 4 shows the host vehicle speed distribution for all drivers with the same grouping rules mentioned above. As can be seen from Fig. 4, the peak value of host vehicle speed frequency in China dataset appeared at the range of $60-70 \mathrm{~km} / \mathrm{h}$, which was lower than the peak range of 70-80 $\mathrm{km} / \mathrm{h}$ in Sweden dataset.

From the shape of Fig. 2 and Fig. 3, one can observe that the time gap has a pretty similar distribution when compared with the gap distance distribution. Furthermore, one can see that the graphs of time gap and gap distance in these two figures have a 'tail' on the right side, while the graph of host vehicle speed in Fig. 4 has a 'tail' on the left side.

In Fig. 5, gap distance, time gap, and host vehicle speed distributions for individual drivers in both datasets are presented. In general, the frequency of each range was more balanced and the peak value of frequency was relatively higher within Sweden dataset (SWE dataset) compared to China dataset (CHN dataset).

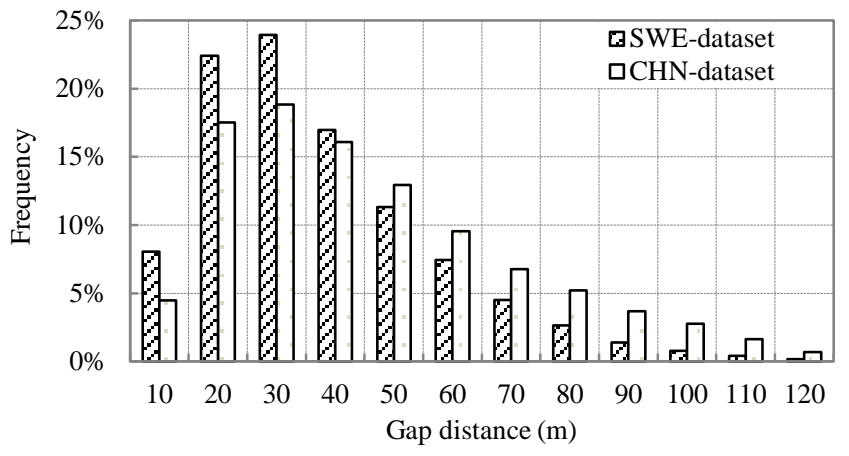

Fig. 2 The gap distance distribution for all drivers

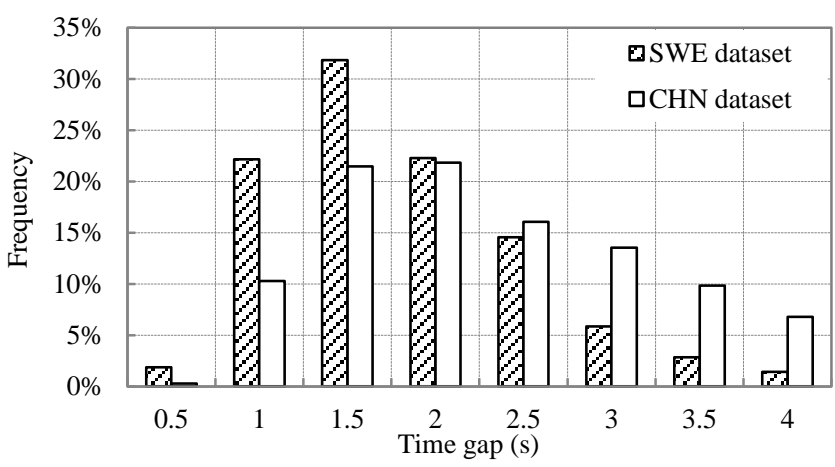

Fig. 3 The time gap distribution for all drivers

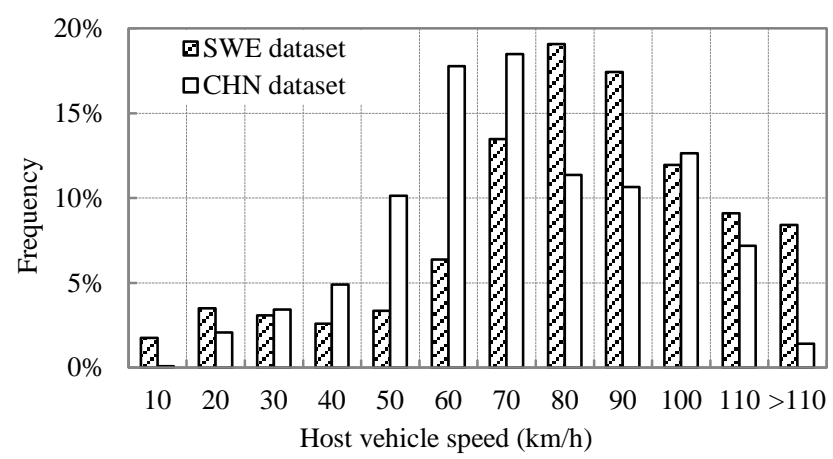

Fig. 4 The host vehicle speed distribution for all drivers
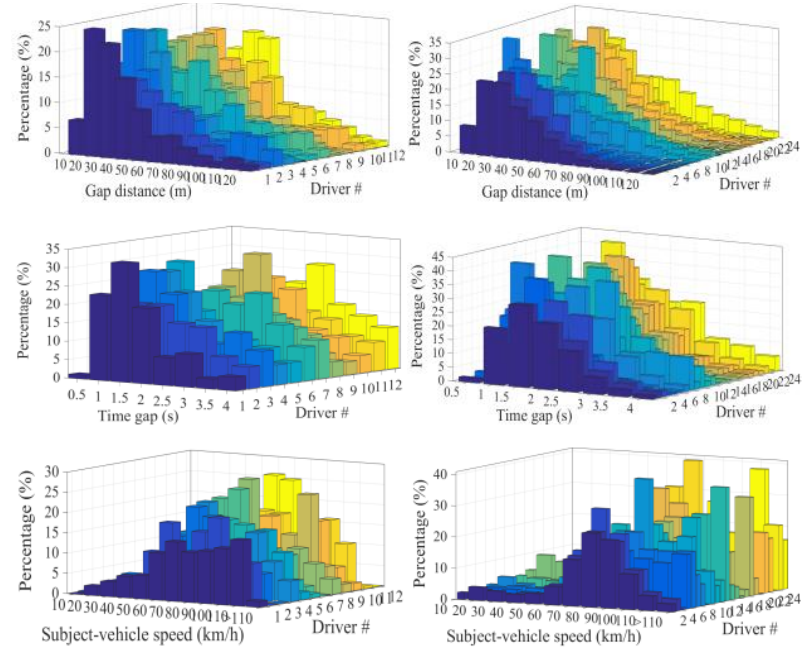

Fig. 5 The gap distance (above), time gap (middle) and speed (below) distributions for individual drivers from China (left) and Sweden (right)

\section{B. Comparison between mean time gap and gap distance among events from both datasets}

Besides the description of gap distance, time gap and host vehicle speed distribution for all drivers, the relationship between the mean host vehicle speed and other indicators such as mean time gap and mean gap distance was analysed among the car-following events from both datasets.

Fig. 6 shows that the mean gap distance increases as host vehicle speed increases $(p<.001, r=.70)$. Whereas Fig. 7 shows almost no correlation between the mean time gap within 1-4s and the mean speed of host vehicles. These indicate that drivers from China and Sweden are inclined to keep a longer distance with the preceding vehicle at a high speed, while they may choose the similar time gap range when following a target vehicle despite their speed conditions in general.


Fig. 6 The mean gap distance distribution among events for CHN dataset (left) and SWE dataset (right)
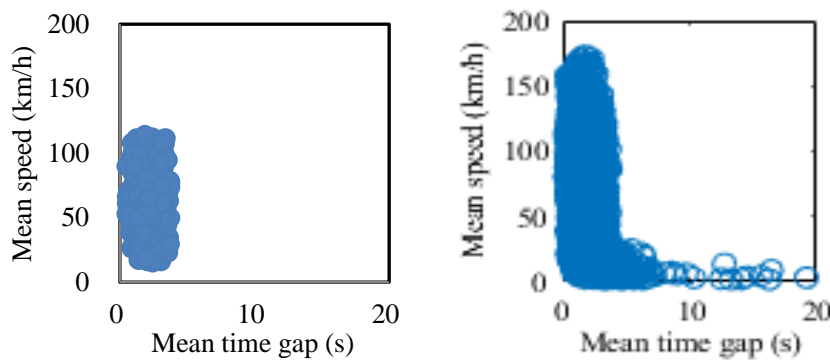

Fig. 7 The mean time gap distribution among events for CHN dataset (left) and SWE dataset (right) 
C. Comparison of time gap and gap distance within different speed limits from both datasets

The previous section showed that the mean gap distance increased along with the mean host vehicle speed but the mean time gap did not seem to be affected by the mean host vehicle speed among the car-following events. In this section, the relationship between gap distance and time gap from a perspective of all car-following data is investigated. As can be observed from Fig. 8, the time gap and gap distance also show the same tendency even in different speed limits. Furthermore, for both China dataset and Sweden dataset, it was found that the span of gap distance was larger at high speed in comparison with that at low speed, while the span of time gap was similar under different speed conditions. In addition, one can see that the median time gap and gap distance from Sweden in different speed limits were lower than the values in China dataset.

To test the effect of the host vehicle speed on time gap and gap distance in different speed limits, two one-way analysis of variance (ANOVA) were conducted using China dataset, with the independent variables of three speed limits (70/90/110 $\mathrm{km} / \mathrm{h}$ ) and the dependent variables of time gap and distance gap, respectively. The values of mean gap distance are $27.89 \mathrm{~m}$ $(\mathrm{SD}=15.35), 48.51 \mathrm{~m}(\mathrm{SD}=19.95)$ and $62.62 \mathrm{~m}(\mathrm{SD}=25.04)$ within the speed limit of 70/90/110 $\mathrm{km} / \mathrm{h}$ road conditions respectively. Similarly, the mean time gap is $1.94 \mathrm{~s}(\mathrm{SD}=0.84)$, $2.17 \mathrm{~s}(\mathrm{SD}=0.82)$, or $2.09 \mathrm{~s}(\mathrm{SD}=0.89)$ when driving on roads with the speed limit of 70/90/110 $\mathrm{km} / \mathrm{h}$, respectively. Moreover, it was found that the host vehicle speed within three speed limits has a significant influence on the time gap $(\mathrm{p}<.001)$ and gap distance $(\mathrm{p}<.001)$. However, the mean time gap within three speed limits is located around $2.0 \mathrm{~s}$.

When similar analysis was performed using the dataset from Sweden, the values of mean gap distance are $26.31 \mathrm{~m}$ $(\mathrm{SD}=15.15), 31.62 \mathrm{~m}(\mathrm{SD}=17.37)$ and $50.93 \mathrm{~m}(\mathrm{SD}=23.57)$ within the speed limit of 70/90/110 $\mathrm{km} / \mathrm{h}$ road conditions respectively. The values of mean time gap are $1.56 \mathrm{~s}$ $(\mathrm{SD}=0.68), 1.43 \mathrm{~s}(\mathrm{SD}=0.66)$ and $1.79 \mathrm{~s}(\mathrm{SD}=0.77)$ within the speed limit of 70/90/110 km/h road conditions respectively. The ANOVA analysis suggests that the host vehicle speed within three speed limits has a significant influence on the time gap $(\mathrm{p}<.001)$ and gap distance $(\mathrm{p}<.001)$. However, the mean time gap within three speed limits is located around $1.5 \mathrm{~s}$. Also, to show the relationship between the gap distance and time gap more clearly, a further comparison was made in Fig. 9 between each other in the format of cumulative frequency within different speed limits.
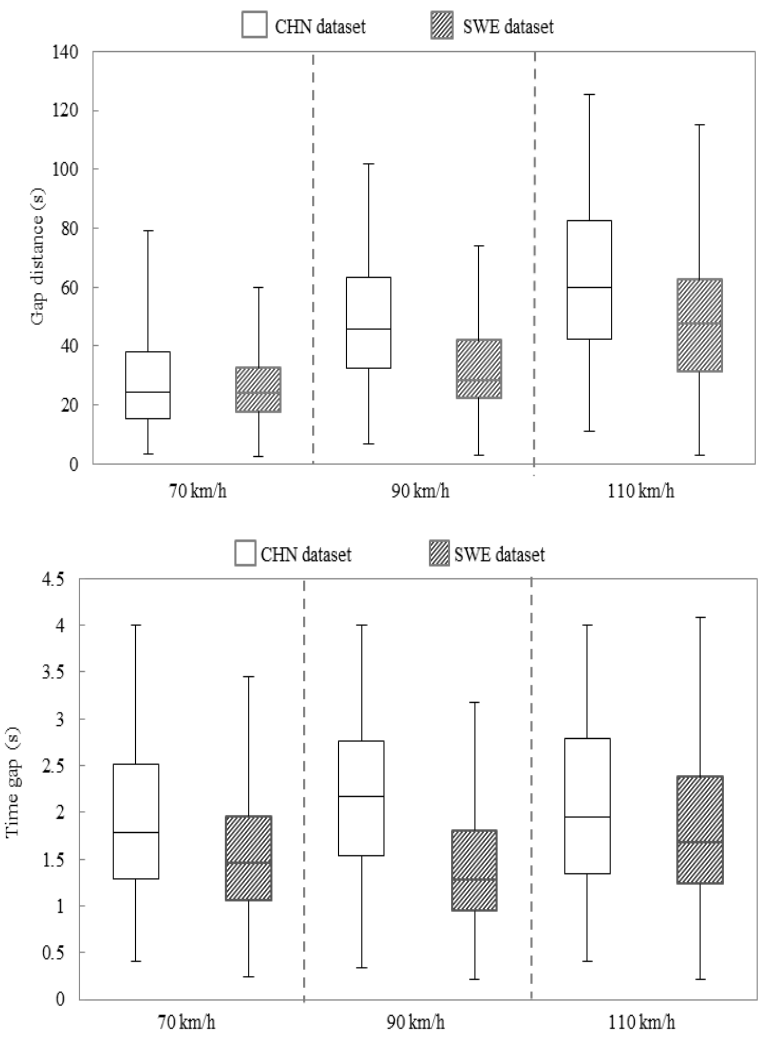

Fig. 8 The gap distance (above) and time gap (below) distribution in three speed limits for both CHN and SWE dataset
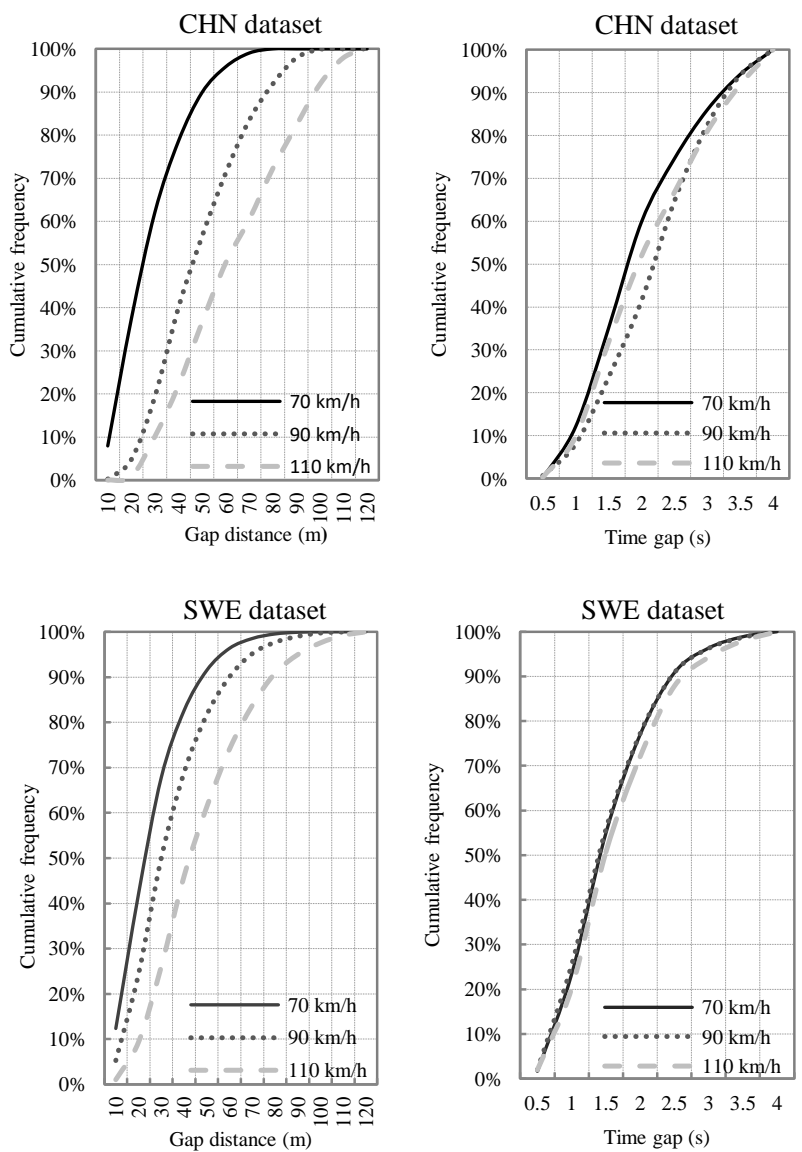

Fig. 9 The gap distance and time gap cumulative frequencies in three speed limits 
D. Comparison of TTC and time gap in various relative speed and host vehicle speed ranges from both datasets

In this section, a comparison of TTC and time gap in various relative speed and host vehicle speed ranges was conducted. Note that the TTC is taken into account for car-following behaviour analysis only when the host vehicle speed is higher than the lead vehicle speed. Hence, relative speed here is defined as $\Delta \mathrm{V}=\mathrm{V}_{\text {host }}-\mathrm{V}_{\text {lead }}$. Considering the relative speed was recorded in the opposite format in Sweden dataset, we only extracted the negative value of Delta- $\mathrm{V}$ on account of TTC would tend to lie along a horizontal line (i.e. nearly 100 seconds) with regard to a positive Delta-V.

For both China and Sweden dataset, when time gap was plotted against TTC, it could be observed that the correlation between them increases as the host vehicle speed range increases (Fig. 10). When plotting time gap and TTC separately against the relative speed (Fig. 11), one could find that at low relative speed $(5-10 \mathrm{~km} / \mathrm{h})$, the mean TTC values are very different for different host vehicle speed ranges, and the difference of mean TTC values for different host vehicle speed ranges decreases as the relative speed range increases. And it was just the opposite for time gap, that is, at low relative speed, the mean time gap values for different host vehicle speed ranges are similar, and this difference of mean time gap values for different host vehicle speed ranges has tendency to increase as the relative speed range increases. Also, for a certain relative speed range depicted in Fig. 11, TTC appears to increase as the host vehicle speed increases, while time gap seems to decrease as the increase of host vehicle speed.

In addition, from Fig. 11 one could see that for different host vehicle speed ranges, time gap has a tendency to increase as the relative speed increases and TTC has a tendency to decrease as the relative speed increases. From Fig. 11, it should also be noted that TTC within low speed ranges $(\mathrm{v}<50$ $\mathrm{km} / \mathrm{h}$ ) is relatively steady in comparison with other host vehicle speed ranges. Likewise, time gap is relatively steady under high speed conditions $(\mathrm{v}>90 \mathrm{~km} / \mathrm{h})$. These suggest that time gap is more suitable to be used as a safety indicator for car-following in high-speed conditions, but a combination of time gap and TTC seem needed to be used as a safety indicator for car-following in low-speed conditions.

To explore what kind of combination ratio of TTC and time gap is appropriate to be a decision threshold for speed control in the low speed ranges, time gap and TTC in various host vehicle speed ranges and relative speed ranges from $\mathrm{CHN}$ and SWE dataset (see Tables 1-4) were analysed. To show the tendency more clearly, as an example, time gap and TTC in the relative speed range of $5-10 \mathrm{~km} / \mathrm{h}$ and $25-30 \mathrm{~km} / \mathrm{h}$ with the speed range of $90-110 \mathrm{~km} / \mathrm{h}$ and $30-50 \mathrm{~km} / \mathrm{h}$ were depicted in Fig. 12. Note that the weighted value of TTC and time gap becomes closer if giving them different proportions (i.e. 50\% TTC $+50 \%$ time gap, or $40 \%$ TTC $+60 \%$ time gap) in two extreme relative speed ranges. However, given that it is not a constant number within different relative speed and speed ranges, there is not enough support to suggest an exact proportion of TTC and time gap to be used as a decision threshold for speed control in the low speed ranges based on the existing results. Therefore, a combination of time gap and TTC (although no exact proportion is given here) is still suggested to be the safety indicator for analysis of car-following behaviours at a low speed range, especially in urban traffic. While at a high speed range, time gap is more appropriate to be used in car-following situations.
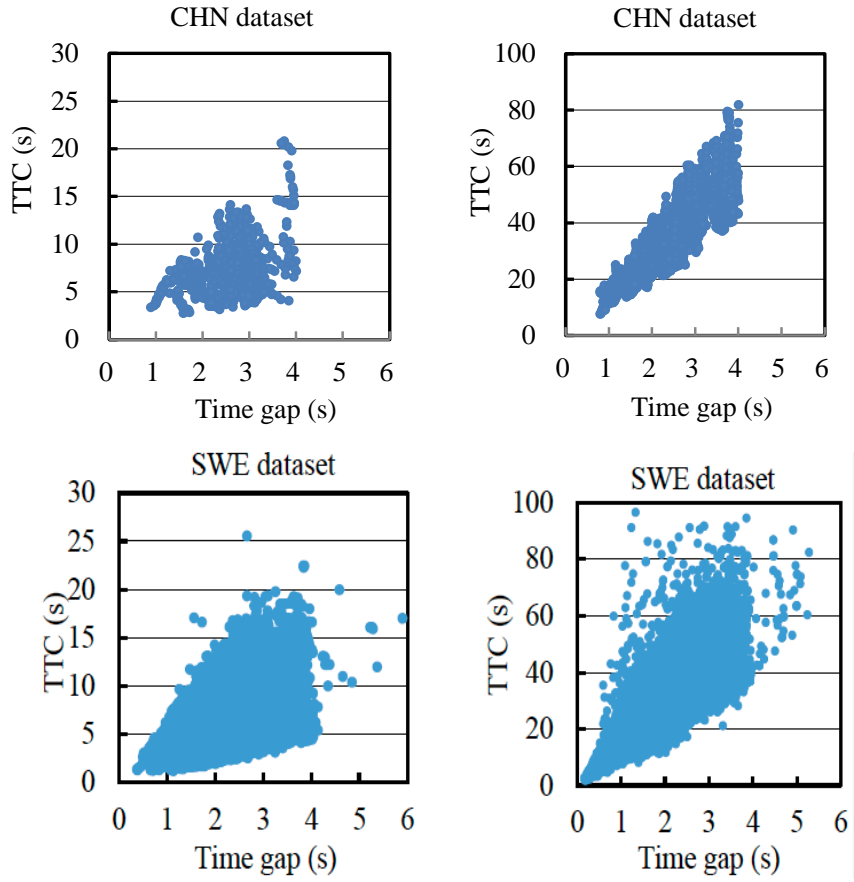

Fig. 10 The time gap and TTC distribution for both CHN dataset (above) and SWE dataset (below) when the host vehicle speed range was 10-30 km/h (left) or $90-110 \mathrm{~km} / \mathrm{h}$ (right) with a relative speed range of $5-10 \mathrm{~km} / \mathrm{h}$
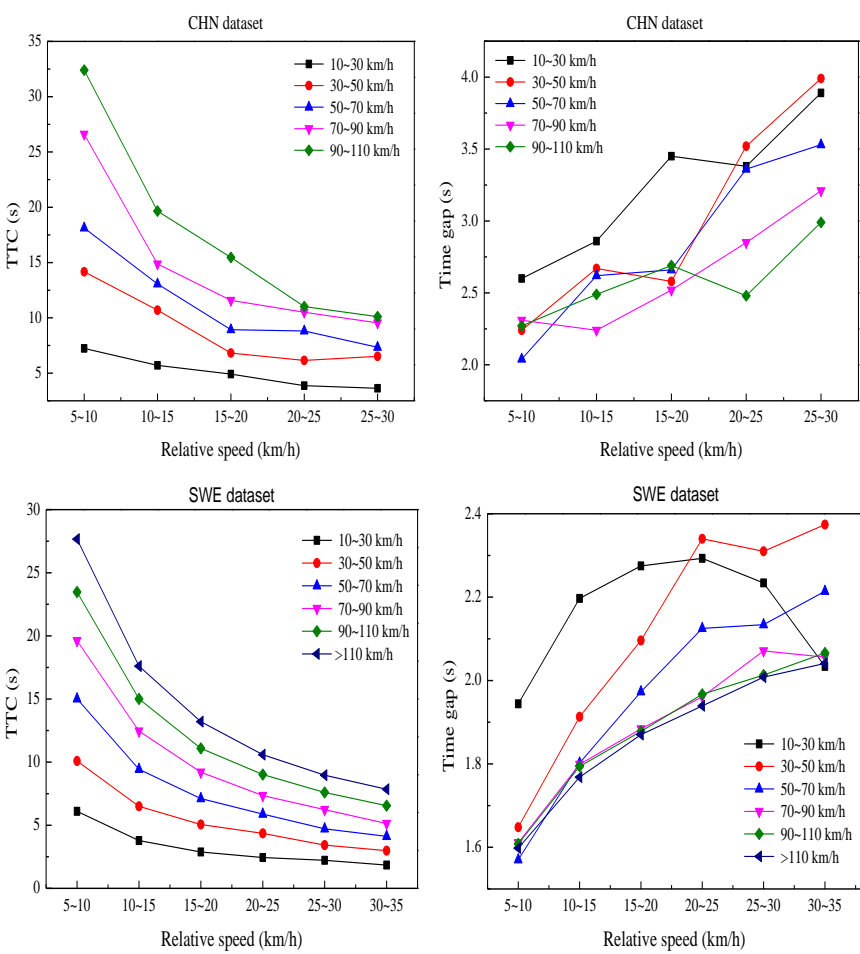

Fig. 11 Mean TTC (left) and time gap (right) in different speed and relative speed ranges for both CHN and SWE dataset 
Table 1 Mean time gap in various speed and relative speed ranges (CHN

\begin{tabular}{c|cccccc}
\hline \multicolumn{7}{c}{ dataset) } \\
Speed range & $\begin{array}{c}5 \sim 10 \\
\mathrm{~km} / \mathrm{h}\end{array}$ & $\begin{array}{c}10 \sim 15 \\
\mathrm{~km} / \mathrm{h}\end{array}$ & $\begin{array}{c}15 \sim 20 \\
\mathrm{~km} / \mathrm{h}\end{array}$ & $\begin{array}{c}20 \sim 25 \\
\mathrm{~km} / \mathrm{h}\end{array}$ & $\begin{array}{c}25 \sim 30 \\
\mathrm{~km} / \mathrm{h}\end{array}$ & $\begin{array}{c}30 \sim 35 \\
\mathrm{~km} / \mathrm{h}\end{array}$ \\
\hline $10 \sim 30 \mathrm{~km} / \mathrm{h}$ & 2.6 & 2.86 & 3.45 & 3.38 & 3.89 & $\mathrm{Na}$ \\
$30 \sim 50 \mathrm{~km} / \mathrm{h}$ & 2.24 & 2.67 & 2.58 & 3.52 & 3.99 & $\mathrm{Na}$ \\
$50 \sim 70 \mathrm{~km} / \mathrm{h}$ & 2.04 & 2.62 & 2.66 & 3.36 & 3.53 & $\mathrm{Na}$ \\
$70 \sim 90 \mathrm{~km} / \mathrm{h}$ & 2.31 & 2.24 & 2.52 & 2.85 & 3.21 & 3.09 \\
$90 \sim 110 \mathrm{~km} / \mathrm{h}$ & 2.27 & 2.49 & 2.69 & 2.48 & 2.99 & 2.28 \\
\hline
\end{tabular}

Table 2 Mean TTC in various speed and relative speed ranges (CHN dataset)

\begin{tabular}{c|cccccc}
$\Delta \mathrm{V}$ & $\begin{array}{c}5 \sim 10 \\
\mathrm{~km} / \mathrm{h}\end{array}$ & $\begin{array}{c}10 \sim 15 \\
\mathrm{~km} / \mathrm{h}\end{array}$ & $\begin{array}{c}15 \sim 20 \\
\mathrm{~km} / \mathrm{h}\end{array}$ & $\begin{array}{c}20 \sim 25 \\
\mathrm{~km} / \mathrm{h}\end{array}$ & $\begin{array}{c}25 \sim 30 \\
\mathrm{~km} / \mathrm{h}\end{array}$ & $\begin{array}{c}30 \sim 35 \\
\mathrm{~km} / \mathrm{h}\end{array}$ \\
\hline $10 \sim 30 \mathrm{~km} / \mathrm{h}$ & 7.24 & 5.71 & 4.92 & 3.87 & 3.63 & $\mathrm{Na}$ \\
$30 \sim 50 \mathrm{~km} / \mathrm{h}$ & 14.17 & 10.7 & 6.82 & 6.15 & 6.52 & $\mathrm{Na}$ \\
$50 \sim 70 \mathrm{~km} / \mathrm{h}$ & 18.13 & 13.07 & 8.93 & 8.82 & 7.34 & $\mathrm{Na}$ \\
$70 \sim 90 \mathrm{~km} / \mathrm{h}$ & 26.61 & 14.87 & 11.58 & 10.51 & 9.55 & 7.14 \\
$90 \sim 110 \mathrm{~km} / \mathrm{h}$ & 32.4 & 19.66 & 15.46 & 11.02 & 10.11 & 6.70 \\
\hline
\end{tabular}

Table 3 Mean time gap in various speed and relative speed ranges (SWE

\begin{tabular}{c|cccccc}
\hline \multicolumn{7}{c}{ dataset) } \\
Speed range & $\begin{array}{c}5 \sim 10 \\
\mathrm{~km} / \mathrm{h}\end{array}$ & $\begin{array}{c}10 \sim 15 \\
\mathrm{~km} / \mathrm{h}\end{array}$ & $\begin{array}{c}15 \sim 20 \\
\mathrm{~km} / \mathrm{h}\end{array}$ & $\begin{array}{c}20 \sim 25 \\
\mathrm{~km} / \mathrm{h}\end{array}$ & $\begin{array}{c}25 \sim 30 \\
\mathrm{~km} / \mathrm{h}\end{array}$ & $\begin{array}{c}30 \sim 35 \\
\mathrm{~km} / \mathrm{h}\end{array}$ \\
\hline $10 \sim 30 \mathrm{~km} / \mathrm{h}$ & 1.94 & 2.20 & 2.28 & 2.29 & 2.23 & 2.03 \\
$30 \sim 50 \mathrm{~km} / \mathrm{h}$ & 1.65 & 1.91 & 2.10 & 2.34 & 2.31 & 2.37 \\
$50 \sim 70 \mathrm{~km} / \mathrm{h}$ & 1.57 & 1.80 & 1.97 & 2.13 & 2.13 & 2.21 \\
$70 \sim 90 \mathrm{~km} / \mathrm{h}$ & 1.61 & 1.80 & 1.88 & 1.96 & 2.07 & 2.06 \\
$90 \sim 110 \mathrm{~km} / \mathrm{h}$ & 1.61 & 1.79 & 1.88 & 1.97 & 2.01 & 2.07 \\
$>110 \mathrm{~km} / \mathrm{h}$ & 1.60 & 1.77 & 1.87 & 1.94 & 2.01 & 2.04 \\
\hline
\end{tabular}

Table 4 Mean TTC in various speed and relative speed ranges (SWE dataset)

\begin{tabular}{c|cccccc}
$\Delta \mathrm{V}$ & $\begin{array}{c}5 \sim 10 \\
\mathrm{~km} / \mathrm{h}\end{array}$ & $\begin{array}{c}10 \sim 15 \\
\mathrm{~km} / \mathrm{h}\end{array}$ & $\begin{array}{c}15 \sim 20 \\
\mathrm{~km} / \mathrm{h}\end{array}$ & $\begin{array}{c}20 \sim 25 \\
\mathrm{~km} / \mathrm{h}\end{array}$ & $\begin{array}{c}25 \sim 30 \\
\mathrm{~km} / \mathrm{h}\end{array}$ & $\begin{array}{c}30 \sim 35 \\
\mathrm{~km} / \mathrm{h}\end{array}$ \\
\hline $10 \sim 30 \mathrm{~km} / \mathrm{h}$ & 6.10 & 3.78 & 2.88 & 2.44 & 2.23 & 1.85 \\
$30 \sim 50 \mathrm{~km} / \mathrm{h}$ & 10.09 & 6.50 & 5.06 & 4.36 & 3.42 & 2.98 \\
$50 \sim 70 \mathrm{~km} / \mathrm{h}$ & 15.01 & 9.43 & 7.12 & 5.89 & 4.72 & 4.12 \\
$70 \sim 90 \mathrm{~km} / \mathrm{h}$ & 19.62 & 12.46 & 9.20 & 7.35 & 6.23 & 5.14 \\
$90 \sim 110 \mathrm{~km} / \mathrm{h}$ & 23.48 & 15.01 & 11.09 & 9.02 & 7.60 & 6.55 \\
$>110 \mathrm{~km} / \mathrm{h}$ & 27.66 & 17.61 & 13.20 & 10.59 & 8.96 & 7.85 \\
\hline
\end{tabular}
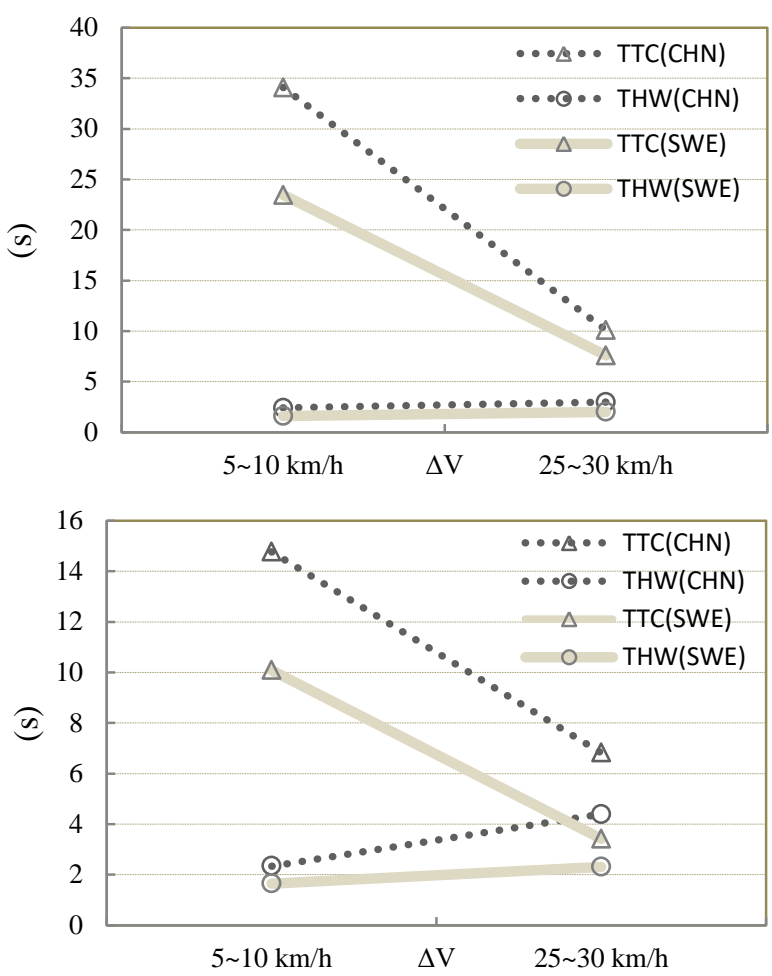

Fig. 12 Mean time gap and TTC in two extreme relative speed ranges with the speed range of $90-110 \mathrm{~km} / \mathrm{h}$ (above) and 30-50 km/h (below) for both CHN dataset and SWE dataset

\section{DISCUSSION}

Here, we compare the results obtained through this study with those from previous research (see Table 5). In this study, the highest frequency of time gap in car-following situations is within the range of $1.5-2.0 \mathrm{~s}$ in the China dataset, which is consistent with the results obtained by [27]. The highest frequency of time gap to the preceding vehicle in the Sweden dataset is in the range of $1.0-1.5 \mathrm{~s}$, which is similar to the results observed in [28] (1.0-1.5s in the speed range of 30-69 $\mathrm{km} / \mathrm{h}$ in the UK, $1.0-1.5 \mathrm{~s}$ in the speed range of $30-49 \mathrm{~km} / \mathrm{h}$ in Japan, 0.5-1.0s in the speed range of $50-69 \mathrm{~km} / \mathrm{h}$ in Japan). The distribution of gap distance in this study is similar to the results in [29]. The highest frequency of gap distance observed in [29] for various kinds of vehicles is within the range of 20-25 m, which is similar to the results obtained from both the China and Sweden datasets (20-30 m).

Although both of the highest frequencies of gap distances are within the range of 20-30 m, the frequency of each gap distance range less than $40 \mathrm{~m}$ in the Sweden dataset, which is higher compared to the frequency of the corresponding range in the China dataset, and the opposite is observed for gap distance ranges greater than $40 \mathrm{~m}$. Likewise, the peak value of time gap in the Sweden dataset is shorter than the peak value in the China dataset, and the ranges of time gap less than $2 \mathrm{~s}$ in the Sweden dataset account for a larger proportion compared to the China dataset. However, the opposite is found for the time gap ranges greater than $2 \mathrm{~s}$. Furthermore, the median time gap and gap distance from the Sweden dataset in different speed limits were also lower than the corresponding values in the China dataset. These differences may be explained by two factors. One is that the participants recruited in China were all professional drivers (driving school instructors), and the whole test routes were in good condition with few traffic jams or congestion. The other can be attributed to a different driving culture (or driving environment, to be more precise), that is, many drivers in China expect that some other drivers might not respect the traffic rules and might have some irregular driving behaviour (i.e. cut in suddenly), which will threaten their safety [30]. Hence, they prefer to keep longer distance deliberately or have a willingness to create gaps in certain situations to avoid a potential side or rear-end crash with other vehicles.

One may question if the differences could be explained by the fact that there are both male and female drivers in the Sweden dataset while there are only male drivers in the China dataset. However, previous research reviewed in [31] gives mixed results on whether there is a relationship between gender and driving behaviour. Further, previous research comparing male and female driver behaviours in Sweden suggest that there are only marginal difference between the two groups, e.g. related to speed and headway driving behaviour [32].

The host vehicle speed distributions of both the China and Sweden datasets are similar for the segments of data where the speed limits are the same. However, the peak value of host vehicle speed frequency in the China dataset was a little bit lower than the peak range in the Sweden dataset. 
For both the China and Sweden datasets, the spread of gap distance at high speed is bigger in comparison with the spread at low speed. Also, the mean gap distance increases along with the increase of speed. This is in line with what was concluded in [29], [33-37]. Time gap shows almost no correlation with the host vehicle speed. This is analogous to the results in [38-40], that is, distance headway increases as the host vehicle speed increases and time headway is nearly constant in different speed ranges. However, time headway is described to decrease as the host vehicle speed increases in [22], [41, 42]. This may has some relationship with the congestion conditions in [41], simulation conditions in [42], and that there were only a few data points in [22].

The characteristics of TTC and time gap under different relative speed and speed conditions were also examined. TTC increases with the increase of host vehicle speed under certain relative speed ranges, while time gap tends to decrease with the increase of host vehicle speed. Specifically, TTC at low speed $(\mathrm{v}<50 \mathrm{~km} / \mathrm{h})$ is relatively steady in comparison with other speed ranges. Likewise, time gap is relatively steady under high speed conditions ( $\mathrm{v}>90 \mathrm{~km} / \mathrm{h}$ ). Therefore, time gap and TTC are suggested to be used together as a combined safety indicator for car-following in low-speed conditions, such as an urban traffic environment, while time gap is recommended as a safety indicator for car-following in high-speed conditions.

Similar to the findings here, the need of including TTC in addition to time headway was also proposed by [26] based on a driving simulator study. In particular they suggest that (TTC+THW)/2 can be used to guide decision making for pedal control in car-following. While our analysis based on real driving data from China and Sweden support the importance of TTC as part of the decision threshold for pedal control in low speed car-following conditions, further research is needed before an exact formula involving TTC and time gap can be specified.

Table 5. A summary of previous research conducted in different locations

\begin{tabular}{|c|c|c|c|c|}
\hline Source & Measures & Related findings & Type of research & Country \\
\hline Ha et al. [27] & THW & $\begin{array}{l}\text { The highest frequency of THW is within the range of }(1.5-2 \mathrm{~s}] \text { for RN118 } \\
\text { national roadway and A6 motorway roads in France. }\end{array}$ & $\begin{array}{l}\text { Real-world } \\
\text { (roadside data from } \\
\text { national road and } \\
\text { motorway) }\end{array}$ & France \\
\hline $\begin{array}{l}\text { Sato \& Akamatsu } \\
{[28]}\end{array}$ & THW & $\begin{array}{l}\text { The highest frequency is } 1.0-1.5 \mathrm{~s} \text { in the speed range of } 30-69 \mathrm{~km} / \mathrm{h} \text { for trunk } \\
\text { roads and motorways in the UK, } 1.0-1.5 \mathrm{~s} \text { in the range of } 30-49 \mathrm{~km} / \mathrm{h} \text { and } \\
0.5-1.0 \mathrm{~s} \text { in the range of } 50-69 \mathrm{~km} / \mathrm{h} \text { for urban roads and a bypass in Japan. }\end{array}$ & $\begin{array}{l}\text { Real-world } \\
\text { (instrumented } \\
\text { vehicle) }\end{array}$ & $\begin{array}{l}\text { Japan and the } \\
\text { UK }\end{array}$ \\
\hline Li et al. [30] & THW & $\begin{array}{l}\text { The average THW around signalised intersections is } 2.5-2.9 \mathrm{~s} \text { in China, } \\
\text { almost } 20-30 \% \text { longer than the value in the Netherlands. }\end{array}$ & $\begin{array}{l}\text { Real-world } \\
\text { (roadside } \\
\text { observation) }\end{array}$ & $\begin{array}{l}\text { China and the } \\
\text { Netherlands }\end{array}$ \\
\hline $\begin{array}{l}\text { Marsden et al. [22]; } \\
\text { Brackstone et al. [41] }\end{array}$ & THW & $\begin{array}{l}\text { THW decreases as the host vehicle speed increases at three sites from three } \\
\text { different countries. }\end{array}$ & $\begin{array}{l}\text { Real-world } \\
\text { (instrumented } \\
\text { vehicle) }\end{array}$ & $\begin{array}{l}\text { UK, France, } \\
\text { and Germany }\end{array}$ \\
\hline Lu et al. [42] & THW & THW decreases as the host vehicle speed increases. & Simulation & China \\
\hline Siebert et al. [39] & THW & THW thresholds do not significantly differ for different speeds. & Driving simulator & Germany \\
\hline Sanik et al. [29] & DHW & $\begin{array}{l}\text { The highest frequency of DHW for all types of vehicles at four collected } \\
\text { segments along multilane highway is } 20-25 \mathrm{~m} \text {; DHW increases with speed. }\end{array}$ & $\begin{array}{l}\text { Real-world (using } \\
\text { roadside video } \\
\text { cameras) }\end{array}$ & Malaysia \\
\hline $\begin{array}{l}\text { Brackstone et al. } \\
\text { [33]; Meng et al. } \\
\text { [34]; Sangster et al. } \\
\text { [36] }\end{array}$ & DHW & DHW increases as the host vehicle speed increases. & $\begin{array}{l}\text { Real-world } \\
\text { (instrumented } \\
\text { vehicle) }\end{array}$ & $\begin{array}{l}\text { UK, China, } \\
\text { and U.S.A }\end{array}$ \\
\hline Yeung \& Wong [37] & $\begin{array}{l}\text { THW \& } \\
\text { DHW }\end{array}$ & $\begin{array}{l}\text { THW is the lowest at } 65 \mathrm{~km} / \mathrm{h} \text { and DHW increases with speed for open } \\
\text { expressway; THW/DHW increases with speed for tunnel expressway. }\end{array}$ & $\begin{array}{l}\text { Real-world (using } \\
\text { video footages of } \\
\text { expressways) }\end{array}$ & Singapore \\
\hline $\begin{array}{l}\text { Puan [38]; } \\
\text { Taieb-Maimon \& } \\
\text { Shinar [40] }\end{array}$ & $\begin{array}{l}\text { THW \& } \\
\text { DHW }\end{array}$ & $\begin{array}{l}\text { DHW increases as the host vehicle speed increases and THW is nearly } \\
\text { constant for different speeds. }\end{array}$ & $\begin{array}{l}\text { Real-world (using } \\
\text { roadside video } \\
\text { cameras) }\end{array}$ & Malaysia \\
\hline Risto \& Martens [35] & $\begin{array}{l}\text { THW \& } \\
\text { DHW }\end{array}$ & $\begin{array}{l}\text { Varying speed affects driver's ability to keep the instructed THW and DHW, } \\
\text { drivers choose smaller than instructed DHW at higher speed ranges. }\end{array}$ & Driving simulator & Netherlands \\
\hline Mai et al. [26] & $\begin{array}{l}\text { THW \& } \\
\text { TTC }\end{array}$ & $\begin{array}{l}\text { (TTC+THW)/2 is suggested as a strategy of decision making for pedal control } \\
\text { in car-following situations }\end{array}$ & Driving simulator & Germany \\
\hline $\begin{array}{l}\text { Liu \& Selpi (In this } \\
\text { research) }\end{array}$ & $\begin{array}{l}\text { Time gap \& } \\
\text { Gap distance } \\
\& \text { TTC }\end{array}$ & $\begin{array}{l}\text { The highest frequency of time gap is within the range of }(1.5-2 \mathrm{~s}] \text { in China and } \\
(1-1.5 \mathrm{~s}] \text { in Sweden, and the highest frequencies of gap distance from both } \\
\text { datasets are located within the range of }(20-30 \mathrm{~m}] \text { for roads with posted speed } \\
\text { limit } 90-110 \mathrm{~km} / \mathrm{h} \text {. Time gap is recommended as the safety indicator in high } \\
\text { speed conditions }(\mathrm{v}>90 \mathrm{~km} / \mathrm{h}) \text {, while a combination of time gap and TTC is } \\
\text { recommended for low speed conditions }(\mathrm{v}<50 \mathrm{~km} / \mathrm{h}) \text {. }\end{array}$ & $\begin{array}{l}\text { Real-world } \\
\text { (instrumented } \\
\text { vehicle) }\end{array}$ & $\begin{array}{l}\text { China and } \\
\text { Sweden }\end{array}$ \\
\hline
\end{tabular}




\section{CONCLUSION}

Similarities and differences of car-following behaviour in China and Sweden in terms of several safety indicators have been analysed, and how these indicators affect drivers' speed control in car-following situations have been examined. The distributions of gap distance, time gap, and host vehicle speed have been presented. Time gap and gap distance among events and in different speed conditions have been compared. The characteristics of TTC and time gap under different relative speed and host vehicle speed conditions have also been described. Results from this study can be summarised as follows:

1. The highest frequency of gap distance is observed in the same value-range in each of the datasets, while the highest frequency of time gap in Sweden dataset is found at a value-range less than the corresponding value-range in China dataset.

2. Considering gap distance is found to be more sensitive to the speed variations in comparison with time gap, it is recommended to use time gap as a safety indicator rather than gap distance in car-following situations.

3. TTC is found to be more steady at low speed $(\mathrm{v}<50 \mathrm{~km} / \mathrm{h})$ compared with TTC at other host vehicle speed ranges. Similarly, time gap is relatively steady under high speed conditions $(v>90 \mathrm{~km} / \mathrm{h})$. Hence, the indicator of time gap is recommended as a safety indicator for car-following in high-speed conditions, and time gap and TTC are recommended to be used together as a combined safety indicator for car-following in low-speed conditions, especially on urban roads.

Limitations of this work include the followings. The China dataset used here is only from 12 drivers. Though 12 drivers seem to be a small number, Higgs and Abbas [43] found that the results from 10 car-drivers in their study gave enough variation. Also, the participants recruited in China are all driving school instructors, so the results obtained from the China dataset may only represent the characteristics of this specific group of drivers.

Based on this study and other comparison studies reviewed here, it seems clear that there are strong environmental influences on driving behaviours. Therefore, future work could look at environmental influences on driving behaviour more closely. For the development of autonomous driving systems that can function well worldwide it would be important to also understand the extent to which lane-change behaviour varies in different countries.

\section{ACKNOWLEDGMENT}

T. Liu and Selpi acknowledge support from China Scholarship Council (201706560015) and Chalmers Area of Advance Transport, respectively. The study was conducted at SAFER Vehicle and Traffic Safety Centre at Chalmers, during Liu's research visit to Chalmers.

\section{REFERENCES}

[1]. Kim, T., Lovell, D.J., Kim, H., and Oh, C., 'Empirical Results of Effects of Various Causal Factors on Car-Following Behavior', Transportation Research Record Journal of the Transportation Research Board, 2010, 2188, (-1), pp. 174-186.

[2]. Bella, F. and D'Agostini, G., 'Combined Effect of Traffic and Geometrics on Rear-End Collision Risk: Driving Simulator Study', Transportation Research Record Journal of the Transportation Research Board, 2010, 2165, (-1), pp. 96-103.

[3]. Hoogendoorn, R., Hoogendoorn, S.P., Brookhuis, K., and Daamen, W., 'Mental Workload, Longitudinal Driving Behavior, and Adequacy of Car-Following Models for Incidents in Other Driving Lane', Transportation Research Record, 2010, 2188, (1), pp. 64-73.

[4]. Liu, T., Selpi, S., and Fu, R., 'The Relationship between Different Safety Indicators in Car-Following Situations', in, 2018 IEEE Intelligent Vehicles Symposium (IV), (IEEE, 2018).

[5]. Manjunatha, P., Vortisch, P., and Mathew, T.V., 'Methodology for the Calibration of Vissim in Mixed Traffic', in, Transportation research board 92nd annual meeting, (2013).

[6]. Bonsall, P., Liu, R., and Young, W., 'Modelling Safety-Related Driving Behaviour-Impact of Parameter Values', Transportation Research Part A: Policy and Practice, 2005, 39, (5), pp. 425-444.

[7]. https://www.korkortsteori.se/avsnitt/trafikregler/avstand, Accessed Date 10 January 2019.

[8]. https://www.gov.uk/government/news/highways-agency-warns-tailgaters -that-only-a-fool-breaks-the-two-second-rule, Accessed Date 10 January 2019.

[9]. Dou, Y., Ni, D., Wang, Z., Wang, J., and Yan, F., 'Strategic Car-Following Gap Model Considering the Effect of Cut-Ins from Adjacent Lanes', IET Intelligent Transport Systems, 2016, 10, (10), pp. 658-665.

[10]. Lee, D.N., 'A Theory of Visual Control of Braking Based on Information About Time-to-Collision', Perception, 1976, 5, (4), pp. 437-459.

[11]. Lu, G., Cheng, B., Lin, Q., and Wang, Y., 'Quantitative Indicator of Homeostatic Risk Perception in Car Following', Safety Science, 2012, 50, (9), pp. 1898-1905.

[12].Pariota, L., Bifulco, G.N., Galante, F., Montella, A., and Brackstone, M., 'Longitudinal Control Behaviour: Analysis and Modelling Based on Experimental Surveys in Italy and the Uk', Accident Analysis \& Prevention, 2016, 89, pp. 74-87.

[13]. Tarko, A.P., 'Use of Crash Surrogates and Exceedance Statistics to Estimate Road Safety', Accident Analysis \& Prevention, 2012, 45, pp. 230-240.

[14]. Minderhoud, M.M. and Bovy, P.H., 'Extended Time-to-Collision Measures for Road Traffic Safety Assessment', Accident Analysis \& Prevention, 2001, 33, (1), pp. 89-97.

[15]. Chen, X.M., Li, L., and Shi, Q., A Markov Model Based on Headway/Spacing Distributions', Stochastic Evolutions of Dynamic Traffic Flow, (Springer, 2015)

[16]. Vogel, K., 'What Characterizes a "Free Vehicle" in an Urban Area?', Transportation Research Part F: Traffic Psychology and Behaviour, 2002, 5, (1), pp. 15-29.

[17]. Evans, L. and Wasielewski, P., 'Risky Driving Related to Driver and Vehicle Characteristics', Accident Analysis \& Prevention, 1983, 15, (2), pp. 121-136.

[18]. Zhao, X., Li, Q., Xie, D., Bi, J., Lu, R., and Li, C., 'Risk Perception and the Warning Strategy Based on Microscopic Driving State', Accident Analysis \& Prevention, 2018.

[19]. Wang, J., Xiong, C., Lu, M., and Li, K., 'Longitudinal Driving Behaviour on Different Roadway Categories: An Instrumented-Vehicle Experiment, Data Collection and Case Study in China', IET Intelligent Transport Systems, 2014, 9, (5), pp. 555-563.

[20]. Houchin, A.J., 'An Investigation of Freeway Standstill Distance, Headway, and Time Gap Data in Heterogeneous Traffic in Iowa', 2015.

[21]. Amini, E., Tabibi, M., Khansari, E.R., and Abhari, M., 'A Vehicle Type-Based Approach to Model Car Following Behaviors in Simulation Programs (Case Study: Car-Motorcycle Following Behavior)', IATSS Research, 2018. 
[22]. Marsden, G.R., Mcdonald, M., and Brackstone, M., 'A Comparative Assessment of Driving Behaviours at Three Sites', 2003, 3, (1), pp. 5-20.

[23]. Sato, T., Akamatsu, M., Zheng, P., and McDonald, M., 'Comparison of Car Following Behavior between Uk and Japan', in, ICCAS-SICE, 2009, (IEEE, 2009).

[24]. Etemad, A. and Kessler, C., 'Eurofot-European Large-Scale Field Operational Test on in-Vehicle Systems', in, 4. Tagung Fahrerassistenz, (2010).

[25]. Selpi, Borgen, S., Bärgman, J., Svanberg, E., Dozza, M., Nisslert, R., Norell, C., Kovaceva, J., Sanchez, D., Saez, M., and Val, C. 'Deliverable D3. 3: Data Management in Eurofot', 2012.

[26]. Mai, M., Wang, L., and Prokop, G., 'Advancement of the Car Following Model of Wiedemann on Lower Velocity Ranges for Urban Traffic Simulation', Transportation Research Part F: Traffic Psychology and Behaviour, 2017.

[27]. Ha, D.-H., Aron, M., and Cohen, S., 'Time Headway Variable and Probabilistic Modeling', Transportation Research Part C: Emerging Technologies, 2012, 25, pp. 181-201.

[28]. Sato, T. and Akamatsu, M., Understanding Driver Car-Following Behavior Using a Fuzzy Logic Car-Following Model', Fuzzy Logic-Algorithms, Techniques and Implementations, (InTech, 2012)

[29]. Sanik, M.E., Prasetijo, J., Nor, M., Hakimi, A., Hamid, N.B., Yusof, I., and Putra Jaya, R., 'Analysis of Car Following Headway Along Multilane Highway', Jurnal Teknologi, 2016, 78, (4), pp. 59-64.

[30]. Li, J., Van Zuylen, H.J., Chen, Y., and Lu, R., 'Comparison of Driver Behaviour and Saturation Flow in China and the Netherlands', IET Intelligent Transport Systems, 2012, 6, (3), pp. 318-327.

[31]. Sagberg, F., Selpi, Bianchi Piccinini, G.F., and Engström, J., 'A Review of Research on Driving Styles and Road Safety', Human factors, 2015 , 57, (7), pp. 1248-1275.

[32]. Aronsson, K. and Bang, K., 'Female and Male Driving Behaviour on Swedish Urban Roads and Streets', in, European Transport Conference (ETC) Association for European Transport (AET), (2006).

[33]. Brackstone, M., Sultan, B., and McDonald, M., 'Motorway Driver Behaviour: Studies on Car Following', Transportation Research Part F: Traffic Psychology and Behaviour, 2002, 5, (1), pp. 31-46.

[34]. Meng, F.-x., Zhang, W., and Wang, J., 'Driver's Car-Following and Lane-Changing Models: An Experimental Study', in, Industrial Engineering and Engineering Management (IE\&EM), 2011 IEEE 18Th International Conference on, (IEEE, 2011).

[35]. Risto, M. and Martens, M.H., 'Time and Space: The Difference between Following Time Headway and Distance Headway Instructions', Transportation Research Part F: Traffic Psychology and Behaviour, 2013, 17, pp. 45-51.

[36]. Sangster, J., Rakha, H., and Du, J., 'Application of Naturalistic Driving Data to Modeling of Driver Car-Following Behavior', Transportation Research Record: Journal of the Transportation Research Board, 2013, (2390), pp. 20-33.

[37]. Yeung, J.S. and Wong, Y.D., 'The Effect of Road Tunnel Environment on Car Following Behaviour', Accident Analysis \& Prevention, 2014, 70, pp. 100-109.

[38]. Puan, O.C., 'Driver's Car Following Headway on Single Carriageway Roads', Malaysian Journal of Civil Engineering, 2004, 16, (2).

[39]. Siebert, F.W., Oehl, M., Bersch, F., and Pfister, H.-R., 'The Exact Determination of Subjective Risk and Comfort Thresholds in Car Following', Transportation Research Part F: Traffic Psychology and Behaviour, 2017, 46, pp. 1-13.

[40]. Taieb-Maimon, M. and Shinar, D., 'Minimum and Comfortable Driving Headways: Reality Versus Perception', Human factors, 2001, 43, (1), pp. 159-172.

[41]. Brackstone, M., Waterson, B., and McDonald, M., 'Determinants of Following Headway in Congested Traffic', Transportation Research Part F: Traffic Psychology and Behaviour, 2009, 12, (2), pp. 131-142.

[42]. Lu, G., Cheng, B., Wang, Y., and Lin, Q., 'A Car-Following Model Based on Quantified Homeostatic Risk Perception', Mathematical Problems in Engineering, 2013, 2013.

[43]. Higgs, B. and Abbas, M., 'Segmentation and Clustering of Car-Following Behavior: Recognition of Driving Patterns', IEEE Transactions on Intelligent Transportation Systems, 2015, 16, (1), pp. $81-90$.

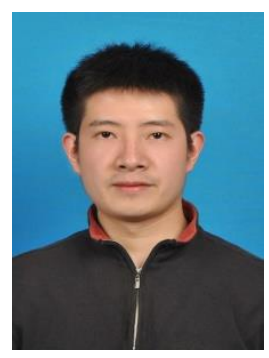

Tong Liu was born in Huairen county, Shanxi province, PR China, in 1989. He received a B.S. degree in traffic engineering from ShanDong JiaoTong University, Jinan, PR China, in 2013, and obtained successive postgraduate and doctoral programs of Chang'an University in vehicle application engineering since 2015 . He is currently a PhD student studying in the School of Automobile, Chang'an University, Xi'an, PR China.

He has participated and conducted several naturalistic-driving studies and data analysis for university and government sponsors. He has worked at the Research Institute of Highway Ministry of Transport (RIOH) of China as an intern in 2015, and has done a research visit to Chalmers University of Technology in Sweden as a visiting $\mathrm{PhD}$ student with the funding support from China Scholarship Council in 2017.

His current research interests include the statistical analysis of naturalistic driving data, data mining, driver behaviour analysis, and driving style classification.

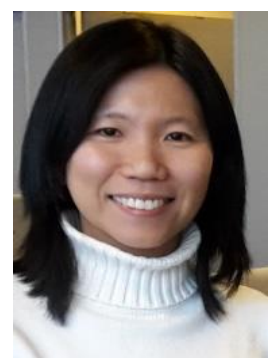

Selpi received a $\mathrm{PhD}$ degree in computing from the Robert Gordon University in the UK in 2008, an MSc degree in bioinformatics from Chalmers University of Technology in Sweden in 2004, and a BSc degree in computer science from the University of Indonesia in 2000.

She currently works at Chalmers. Her current research interests include applications of machine learning and data mining for transport-related domain (e.g., understanding driving styles/driver behaviour from naturalistic driving data, travel time and traffic volume predictions, text-mining for text data in transport) and the impact of mixed traffic on traffic safety and efficiency. Beside academic work, she has several years of experiences in software industry.

Dr. Selpi is a member of the IEEE Intelligent Transportation Systems Society's technical committee on Naturalistic Driving Data Analytics. She has served as a reviewer and an associate editor for several IEEE conferences. 